\title{
The lord of the rings
}

\author{
Antonio Miceli, MD, PhD
}

\author{
From the Centro Cardiotoracico, Istituto Clinico Sant'Ambrogio, Gruppo Ospedaliero SanDonato, Milan, Italy. \\ Disclosures: Miceli is a consultant for Livanova. \\ Received for publication Aug 18, 2017; accepted for publication Aug 26, 2017; available ahead of print Sept 21, \\ 2017. \\ Address for reprints: Antonio Miceli, MD, PhD, Centro Cardiotoracico, Istituto Clinico Sant'Ambrogio, Gruppo \\ Ospedaliero SanDonato, Via Faravelli 16, Milano, Italia (E-mail: antoniomiceli79@alice.it). \\ J Thorac Cardiovasc Surg 2017;154:1925-6 \\ $0022-5223 / \$ 36.00$ \\ Copyright (C) 2017 by The American Association for Thoracic Surgery \\ http://dx.doi.org/10.1016/j.jtcvs.2017.08.084
}

The rules for mitral valve repair for degenerative mitral valve regurgitation include the preservation or restoration of normal leaflet motion; the creation of a large surface of coaptation; and, most importantly, the stabilization of the entire annulus with an annuloplasty. ${ }^{1}$ According to Carpentier and colleagues, ${ }^{2}$ annuloplasty is a primary component in mitral valve repair because it restores the size and shape of the native annulus, prevents future annular dilatation, and provides functional annular support.

A wide variety of rings, including rings that are flexible, semirigid, or rigid; incomplete or complete; or planar or saddle-shaped have been developed with the aim to restore the anatomic and physiologic function of a mitral valve apparatus and optimize leaflet coaptation. However, the characterization and selection of different annuloplasty devices remains largely qualitative and often a matter of surgeon's preference rather than an evidence-based selection. ${ }^{3}$ In this issue, Kawamoto and colleagues ${ }^{4}$ explore the influence of prosthetic ring selection in patients undergoing mitral valve repair for type II mitral valve regurgitation according to the location of leaflet prolapse. The recurrence of mitral regurgitation over the time was higher in patients who had a correction for anterior or bileaflet prolapse with a partial band compared with those receiving a full rigid or semirigid ring. Specifically, the respective 5- and 10-year freedoms from mitral insufficiency $\geq 3$ were $79.6 \%$ and $68.9 \%$ for partial band and $88.2 \%$ and $80.2 \%$ for full ring repair, respectively. Multivariable analysis showed the use of a partial band was the only independent risk factor for mitral insufficiency $\geq 3$ at follow-up in the anterior group. Conversely, the choice of prosthetic ring did not influence the recurrence of mitral regurgitation in patients with a posterior prolapse.

The outcomes reported by Kawamoto and colleagues ${ }^{4}$ are excellent: the freedom from reoperation at 5 and 10 years was $98 \%$ and $96.3 \%$ in the posterior group and $92.8 \%$ and $84.6 \%$ in anterior group, respectively, and they confirm that mitral valve repair for anterior or bileaflet prolapse are more challenging and often associated with suboptimal results at follow-up. These results have been extensively described elsewhere; however, the novelty of this study consists in evaluating the influence of type of ring prosthesis on the

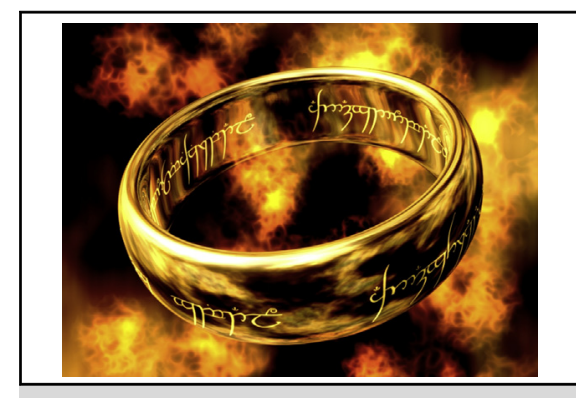

One Ring from The Lord of the Rings by J. R. R. Tolkien.

\section{Central Message}

A complete semirigid ring is the solution for all types of degenerative mitral valve regurgitation.

See Article page 1915.

recurrence of mitral regurgitation over time. ${ }^{5-7}$ Specifically, in the anterior group, the use of a partial band was associated with 3-fold increased risk of recurrence of mitral regurgitation, suggesting the preferred use of a full rigid or semirigid ring in these setting of patients.

Flexible partial bands are particularly designed to preserve the 3-dimensional contour of the native annulus and its dynamic function. However, these bands present some drawbacks. First, it has been shown that a band may become rigid due to a pannus formation with subsequent fibrotic changes and calcification over time, altering the annular saddle shape and sphincter mechanism of the mitral valve. Second, a flexible band is inappropriate in the presence of a flattened and enlarged native annulus due to chronic mitral regurgitation. ${ }^{3}$ Finally, it is unable to restore the 3:4 (vertical:transverse) annular physiologic relationship proposed by Carpentier and colleagues.,3 These reasons might partially explain the worse outcomes in the anterior groups; however, results were not confirmed in the posterior group. Despite these concepts, the study is limited by the different techniques used for the treatment of the anterior/bilealfet or posterior prolapse. Specifically, the resection and suturing technique associated with a partial band was the main choice for approaching a patient with a posterior prolapse, whereas the use of chordal replacement and full ring was the primary choice for anterior/bileaflet prolapse. It would have been interesting to compare patients receiving similar techniques in both groups. Another important limitation is the lack of information regarding the annular flattening 
and its dilatation, which appears to be more frequent in patients with anterior leaflet or bileaflet prolapse and often the results of a long-term severe chronic mitral regurgitation. ${ }^{3}$ Early surgery is often offered to patients with isolated posterior prolapse because repair is less complex than approaching a patient with anterior or Barlow disease. At this stage, the native mitral annular anatomy (saddle shape) is still conserved and a simple flexible band may preserve the 3-dimensional contour of the native annulus and its dynamics. Conversely, a more rigid ring might be appropriate in the presence of annular flattening and annular dilatation because this method restores the annular geometry and its function. In light of that, a semirigid complete ring may be a good solution for all types of degenerative mitral valve regurgitations because it provides rigidity for annulus remodeling but maintains the flexibility to mimic the natural physiologic movement of an annulus during the cardiac cycle. It is probably the ring of all rings. The lord of rings!

\section{References}

1. Carpentier A. Cardiac valve surgery-the "French correction" J Thorac Cardiovasc Surg. 1983;86:323-37.

2. Carpentier AF, Lessana A, Relland JY, Belli E, Mihaileanu S, Berrebi AJ, et al. The "physio-ring:" an advanced concept in mitral valve annuloplasty. Ann Thorac Surg. 1995;60:1177-85; discussion 1185-86.

3. Wan S, Lee AP, Jin CN, Wong RH, Chan HH, Ng CS, et al. The choice of mitral annuloplastic ring_beyond "surgeon's preference" Ann Cardiothorac Surg. 2015;4:261-5.

4. Kawamoto N, Fujita T, Fukushima S, Hata H, Shimahara Y, Asakura K, et al. Should annuloplasty prosthesis be selected dependent on the location of prolapse in mitral valve repair for type II dysfunction? J Thorac Cardiovasc Surg. 2017; 154:1915-24.e6.

5. Braunberger E, Deloche A, Berrebi A, Abdallah F, Celestin JA, Meimoun P, et al. Very long-term results (more than 20 years) of valve repair with Carpentier's techniques in nonrheumatic mitral valve insufficiency. Circulation. 2001;104:I8-11.

6. David TE, Armstrong S, McCrindle BW, Manlhiot C. Late outcomes of mitral valve repair for mitral regurgitation due to degenerative disease. Circulation. 2013;127:1485-92.

7. Glower DD. Surgical approaches to mitral regurgitation. J Am Coll Cardiol. 2012; 60:1315-22.

8. Luk A, Jegatheeswaran A, David TE, Butany J. Redo mitral valve surgery: morphological features. Cardiovasc Pathol. 2008;17:309-17. 